\title{
Efeito do número de larvas de Boophilus microplus (Can., 1887) (Acari: Ixodidae) sobre a recuperação de fêmeas ingurgitadas em coelhos
}

\section{The effect of Boophilus microplus (Can., 1887) (Acari: Ixodidae) larvae number on the engorged females recovered in rabbits}

\author{
Cláudia Lúcia Guimarães da Silva, Daisy Wilwerth da Cunha, Erik Daemon, João Luiz Horácio Faccini
}

\section{Resumo}

Avaliou-se o efeito da variação do número de larvas e sua relação com a produção final de fêmeas ingurgitadas. Para as infestações, foram utilizadas alíquotas de 2,5; 5,0; 10,$0 ; 20,0 ; 40,0 ; 80,0$ e 160,0 mg de ovos, correspondentes a 50,100, 200,400, 800, 1600 e 3200 larvas de Boophilus microplus por coelho, com três repetições por tratamento.

A melhor produção de fêmeas foi obtida com infestação de 800 larvas, com 130 fêmeas ingurgitadas recuperadas. Destas, $74,62 \%$ realizaram oviposição. O percentual de eclosão das larvas nesta alíquota foi $96,65 \%$. O índice de eficiência reprodutiva e o índice de eficiência nutricional para esta alíquota foram, respectivamente, $29,10 \%$ e $50,32 \%$. Ressaltou-se que o coelho pode ser usado como hospedeiro para $B$. microplus quando um grande número de fêmeas não for necessário.

Palavras chave: Boophilus microplus; infestação experimental; coelho

\section{Introdução}

Boophilus microplus, vulgarmente conhecido como carrapato dos bovinos, é a única espécie do gênero conhecida no Brasil (Famadas e Faccini, 1989). Castro e Pereira (1946) e Srivastava et al. (1987), em trabalhos experimentais com este ixodídeo, utilizaram coelhos como hospedeiros alternativos para estudos sobre o mecanismo de alimentação do carrapato e reações imunes do hospedeiro a partir da alimentação de larvas. No entanto, Loomis (1971) e Srivastava et al. (1986), na tentativa de utilizar o coelho como hospedeiro alternativo, consideraram-no inadequado, porque o ixodídeo não conseguiu completar sua fase parasitária.

Cunha (1978), estudando lesões macroscópicas causadas por diferentes espécies de ixodídeos, sempre utilizou nas infestações toda a progênie das fêmeas e observou o efeito de agregação das larvas de $B$. microplus nas orelhas do coelho, obtendo ao final, fêmeas em número e tamanhos reduzidos, embora não tenham sido pesadas.

O objetivo do presente trabalho foi reavaliar a utilização do coelho como hospedeiro experimental de $B$. microplus e testar o efeito do número de larvas utilizadas nas infestações sobre o número de fêmeas ingurgitadas recuperadas.

\section{Material e Métodos}

Os experimentos foram conduzidos no Laboratório de Ixodologia da Estação para Pesquisas Parasitológicas W.O. Neitz (EPPWON) do Departamento de Parasitologia Animal da Universidade Federal Rural do Rio de Janeiro, localizada no município de Seropédica, RJ, no período de junho de 1993 a julho de 1994.

Para a obtenção de larvas, foram utilizadas 80 fêmeas ingurgitadas provenientes de bovinos da EPPWON, as quais, depois de limpas e pesadas em balança analítica, foram fixadas pelo dorso, com esparadrapo impermeável, em placa de Petri de $120 \mathrm{~mm} \times 12 \mathrm{~mm}$, devidamente identificadas e posteriormente transferidas para estufa para $B O D$ regulada a temperatura de $27 \pm 1^{\circ} \mathrm{C}, \mathrm{R} R>80 \%$ e $22 \mathrm{~h}$ de escotofase.

Após o início da postura, a massa de ovos de cada fêmea foi coletada a cada três dias e transferida para uma placa de Petri para obtenção de uma amostra homogênea dos ovos de todas as posturas, sendo utilizados, para a obtenção das larvas, os ovos coletados do $3^{\circ}$ ao $6^{\circ}$ dia de oviposição (Bennett, 1974; Alvarado e Gonzales, 1979). Em seguida, os ovos foram separados em alíquotas de 2,$5 ; 5,0 ; 10,0 ; 20,0 ; 40,0 ; 80,0$ e $160,0 \mathrm{mg}$, correspondentes a $50,100,200,400,800,1600$ e 3200 larvas, respectivamente, e acondicionadas em seringas descartáveis de $5,0 \mathrm{ml}$, previamente preparadas. Foram utilizados três coelhos Nova Zelândia x Califórnia, todos com aproximadamente $1,5 \mathrm{~kg}$ para cada alíquota, segundo a técnica de Neitz et al. (1971), totalizando três repetições para cada alíquota. Nenhum coelho foi reinfestado. Todas as infestações foram feitas simultaneamente, no intuito de eliminar a influência do fator ambiente (mesoclima). 
Foram feitas observações diárias a partir das infestações para acompanhamento do ciclo até a recuperação de fêmeas ingurgitadas.

Os índices de eficiência reprodutiva (IER) e nutricional (IEN) foram calculados segundo Bennett (1974).

\section{Resultado e Discussão}

As observações diárias, a partir da infestação, demonstraram $100 \%$ de fixação das larvas da alíquota de 50 larvas e de 90a 95\% de fixação nas demais alíquotas. É possível que tal fato tenha ocorrido porque em número reduzido as larvas não precisam competir entre si pelo espaço e pelo melhor local de fixação, a extremidade e as bordas do pavilhão auricular, fato também observado por Cunha (1978).

As perdas observadas durante a fase parasitária não se devem ao hospedeiro, pois Bennett (1974) observou situação semelhante utilizando bovinos, o hospedeiro principal de B. microplus. Estas perdas, possivelmente, devem-se ao fato dos ixodídeos encontrarem-se agregados na borda do pavilhão auricular do coelho, fato já observado por Cunha (1978), e ao ocorrer a ecdise, os novos ínstares não encontravam espaço físico para fixação, propiciando seu desprendimento. Os ínstares que se desprenderam vivos não conseguiram retornar ao pavilhão auricular, morrendo em seguida, diferindo do que foi observado por Mason e Norval (1981) que verificaram, a campo, que ninfas desprendidas de bovinos conseguiram retornar e fixar-se ao mesmo ou em outro animal do rebanho.

A fase parasitária, cuja média é de 21 dias em bovinos, teve duração de 24 a 31 dias. O período de préoviposição foi semelhante ao encontrado nas fêmeas ingurgitadas em bovinos, em média três dias (Alvarado e Gonzales, 1979; Benavides, 1984; Gloria et al., 1993).

Em cada alíquota testada o total de fêmeas ingurgitadas variou (Tabela 1). Estas apresentaram coloração amarelada, em contraste com o aspecto plúmbeo daquelas coletadas em bovinos. A média de peso, apre-

Tabela 1 - Número de fêmeas ingurgitadas de Boophilus microplus obtidas de coelhos infestados com diferentes quantidades de larvas

\begin{tabular}{ccccr}
\hline \multirow{2}{*}{$\begin{array}{c}\text { Número } \\
\text { de larvas }\end{array}$} & \multicolumn{4}{c}{ Número de fêmeas ingurgitadas/coelho } \\
\cline { 2 - 5 } & Coelho 1 & Coelho 2 & Coelho 3 & Total \\
\hline 50 & - & 1 & - & 1 \\
100 & - & - & 1 & 1 \\
200 & - & - & - & - \\
400 & 5 & 2 & 2 & 9 \\
800 & 21 & 48 & 61 & 130 \\
1600 & 7 & 3 & 2 & 12 \\
3200 & 6 & 2 & 10 & 18 \\
\hline
\end{tabular}

sentada na Tabela 2, foi inferior às médias de peso de fêmeas coletadas de bovinos, entre 160 e $395 \mathrm{mg}$, segundo Bennett (1974), Davery et al. (1981) e Benavides (1984), independente da alíquota.

A maioria das fêmeas com peso igual ou superior a $34,65 \mathrm{mg}$ efetuou postura fértil. $\mathrm{Na}$ alíquota de 800 larvas foi observado melhor desempenho na produção de fêmeas ingurgitadas, na média de peso das fêmeas ingurgitadas por alíquota, no percentual de oviposição, percentual de eclosão, IER e IEN (Tabela 2).

Tabela 2 - Número de fêmeas ingurgitadas, peso médio de fêmeas, percentual de oviposição, percentual de postura fértil, percentual de eclosão, índice de eficiência reprodutiva (IER) e índice de eficiência nutricional (IEN) de Boophilus microplus alimentado em coelhos

\begin{tabular}{lccc}
\hline & \multicolumn{3}{c}{ Número de, larvas } \\
\cline { 2 - 4 } Parâmetros & 800 & 1600 & 3200 \\
\hline No de fêmeas & 130 & 12 & 18 \\
peso (mg) $\times \pm 38,88$ & $26,82 \pm 12,61$ & $24,31 \pm 10,82$ & \\
Variação & $11,0-171,4$ & $13,4-49,6$ & $11,8-42,3$ \\
\% oviposição & 74,62 & 25,00 & 50,00 \\
\% postura fértil & 95,88 & 33,33 & 77,78 \\
$\%$ de eclosão & 96,65 & 92,00 & 80,00 \\
IER & 29,10 & 28,88 & 23,64 \\
IEN & 50,32 & 33,81 & 32,55 \\
\hline
\end{tabular}

O desempenho das alíquotas de 50, 100, 200 e 400 larvas foi bem inferior às demais, provavelmente pela ausência de machos, ou pela presença esporádica destes nestas alíquotas.

Srivastava et al. (1986) infestando coelhos com 200 larvas de $B$. microplus não recuperou nenhuma fêmea ingurgitada, como foi observado neste trabalho.

Nas alíquotas de 1600 e 3200 larvas, o número de fêmeas ingurgitadas recuperadas e sua respectiva produção também foram baixos. Isto pode estar relacionado ao grande número de indivíduos no pavilhão auricular do hospedeiro, o que pode ter gerado competição entre eles.

O período de oviposição foi mais curto (5 a 7 dias), quando comparado ao período de oviposição de fêmeas coletadas de bovinos, provavelmente devido ao baixo peso das fêmeas ingurgitadas.

Embora o IER tenha sido considerado baixo $(29,10 \%)$, quando comparado ao IER de exemplares coletados de bovinos (58\%), o IEN $(50,32 \%)$ foi considerado satisfatório na alíquota de 800 larvas, também quando comparado com aqueles coletados em bovinos (78\%), uma vez que o peso médio das fêmeas ingurgitadas esteve abaixo do peso médio das fêmeas coletadas de bovinos, segundo Glória et al. (1993).

Os exemplares da alíquota de 800 larvas apresentaram $96,65 \%$ de eclosão de larvas. Embora o percentual de 
eclosão nas alíquotas de 1600 e 3200 larvas tenha sido alto (92 e $80 \%$, respectivamente), a performance geral destas alíquotas não foi satisfatória. Na alíquota de 1600 larvas apenas uma fêmea fez postura fértil e em ambas as alíquotas o número de fêmeas recuperadas foi inferior à alíquota de $40 \mathrm{mg}$ (Tabela 1).

Os resultados obtidos demonstraram que a variação no número de larvas nas infestações de $B$. microplus em coelhos influencia na produção final de fêmeas ingurgitadas, e que a alíquota de 800 larvas é a mais indicada para a obtenção de fêmeas ingurgitadas capazes de realizar postura fértil. Deve-se ressaltar que a utilização do coelho é limitada quando há necessidade de obtenção de um grande número de fêmeas ingurgitadas.

\section{Abstract}

The effect of Boophilus microplus (Can., 1887) (Acari: Ixodidae) larvae number on the engorged females recovered in rabbits

The larvae number variations and its relation to the engorged females productions were evaluated. Infestations with $2.5 ; 5.0 ; 10.0 ; 20.0 ; 40.0 ; 80.0$ and $160.0 \mathrm{mg}$ corresponding respectively to $50,100,200,400,800,1000$ and 3200 larvae of Boophilus microplus were performed using three rabbit by aliquote. The infestation with 800 larvae yielded 21, 48 and 61 engorged females per rabbit (total of 130). The highest production of females oviposition was seen in $74.62 \%$ of these females with $96.65 \%$ of eclosion. The reproductive efficiency index and nutritional efficiency index were $29.10 \%$ and $50.32 \%$ respectively. It was suggested that the rabbit might be used as host for $B$. microplus when a small number of females is sufficient.

Key words: Boophilus microplus; experimental infestation; rabbit

\section{Referências bibliográficas}

ALVARADO, R.U., GONZALES, J.C. A postura e a viabilidade do Boophilus microplus (Canestrini, 1887) (Acarina, Ixodidae) em condições de laboratório. Rev. Lat.-amer.
Microbiol., v. 21, p. 31-36, 1979.

BENAVIDES, E.O. Biologia oviposicional de la garrapata en condiciones de los llanos orientales de Colombia. Rev. Inst. Colombiano Agropecuário, v. 19, p. 25-32, 1984.

BENNETT, G.F. Boophilus microplus (Canestrini) (Acaridae: Ixodidae) on the bovine host. I. Mortality during the developmental cycle. Acarologia, v. 14, p. 643-650, 1974.

CASTRO, M.P., PEREIRA, C. Alimentação de proteroninfas de Boophilus (Uroboophilus) microplus Can., 1888 (Ixodidae) com os restos necróticos da reação tissular do hospedeiro. Arq. Inst. Biol., v. 17, p.149-161, 1946.

CUNHA, D.W. Estudos da toxidez de alguns carrapatos comumente encontrados no Brasil (Acarina: Ixodidae). Itaguaí, $1978.88 \mathrm{pp}$. Tese de Mestrado, Universidade Federal Rural do Rio de Janeiro.

DAVERY, R. B., GARZA Jr., J., THOMPSON, G.D., DRUMMOND, R.O. Oviposicional biology of the southern cattle tick (Acari: Ixodidae), in the Laboratory. J. Med. Entomol., v. 17, p. 117121, 1981.

FAMADAS, K.M., FACCINI, J.L.H. Variação morfológica de Boophilus microplus (Canestrini, 1887) (Acari: Ixodidae) no Brasil. Arq. Univ. Fed. Rur. Rio de J., v. 12, p. 65-72, 1989.

GLORIA, M.A., FACCINI, J.L.H., DAEMON, E., GRISI, L. Biologia comparativa da fase não parasitária de estirpes de Boophilus microplus (Can., 1887) resistente e sensivel a carrapaticidas em condições de laboratório. Rev. Bras. Parasitol. Vet., v. 2, n. 2, p. 79-84, 1993.

LOOMIS, E.C. Rearing of Booophilus microplus (Acarina: Ixodidae) on the laboratory rabbit. Entomol. Soc. Amer. Ann.,v. 64, p. 598-603, 1971.

MASON, C.A., NORVAL, R.A.I. The transfer of Boophilus microplus (Acarina: Ixodidae) from infested to uninfested cattle under field conditions. Vet. Parasitol., v. 8, p. 185-188, 1981.

NEITZ, W.O., BOUGHTON, F., WALTERS, H.S. Laboratory investigations on the life-cycle of the Karoo paralysis tick (Ixodes rubicundus Neuman, 1904). Onderspoort J. Vet. Res., v. 38, p. 215-224, 1971.

SRIVASTAVA, P.S., LATA, K., SINHA, R.P. Artificial indution of immunity in rabbits through repeated application of Boophilus microplus larvae. Indian J. Anim. Sci., v. 58, p. 1065-1068, 1987.

SRIVASTAVA, S.C., MISHRA, A.K., SHARMA, N.M Rabbit a host of Boophilus microplus (Canestrini, 1888). Indian J. Parasitol., v. 10, p. $245,1986$. 